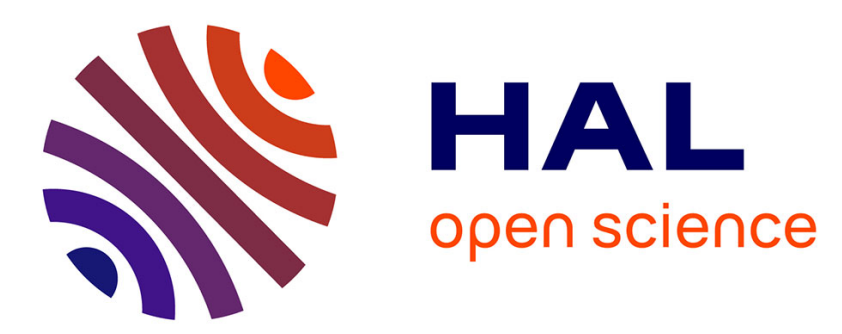

\title{
Analytical expressions of the turn on delay and the rise time of very fast Josephson junctions
}

\author{
A. de Lustrac, P. Crozat, R. Adde
}

\section{To cite this version:}

A. de Lustrac, P. Crozat, R. Adde. Analytical expressions of the turn on delay and the rise time of very fast Josephson junctions. Revue de Physique Appliquée, 1988, 23 (12), pp.1861-1867. 10.1051/rphysap:0198800230120186100 . jpa-00246015

\section{HAL Id: jpa-00246015 https://hal.science/jpa-00246015}

Submitted on 1 Jan 1988

HAL is a multi-disciplinary open access archive for the deposit and dissemination of scientific research documents, whether they are published or not. The documents may come from teaching and research institutions in France or abroad, or from public or private research centers.
L'archive ouverte pluridisciplinaire HAL, est destinée au dépôt et à la diffusion de documents scientifiques de niveau recherche, publiés ou non, émanant des établissements d'enseignement et de recherche français ou étrangers, des laboratoires publics ou privés. 


\title{
REVUE DE PHYSIQUE APPLIQUÉE
}

Revue Phys. Appl. 23 (1988) 1861-1867

DÉCEMBRE 1988, PAGE 1861

Classification

Physics Abstracts

74-50

\section{Analytical expressions of the turn on delay and the rise time of very fast Josephson junctions}

\author{
A. de Lustrac, P. Crozat and R. Adde \\ Institut d'Electronique Fondamentale, Laboratoire associé au C.N.R.S., Bâtiment 220, Université Paris-Sud, \\ 91405 Orsay, France
}

(Reçu le 11 mars 1988, accepté le 29 août 1988)

\begin{abstract}
Résumé. - Nous développons des expressions analytiques approchées du temps de retard au déclenchement et du temps de montée des jonctions Josephson rapides (1-5 ps). Les principales configurations rencontrées en logique Josephson à couplage direct sont traitées et les résultats obtenus sont comparés avec ceux issus du modèle RSJC. De telles expressions sont utiles dans les étapes initiales de la conception de circuits logiques optimisés en vitesse.
\end{abstract}

\begin{abstract}
We develop approximate analytical expressions of the turn on delay and the rise time for very fast Josephson junctions (1-5 ps). Such expressions are useful in the first steps of circuit design with speed optimisation. The principal configurations met in direct coupled Josephson logic circuits are treated and the results are compared with the corresponding quantities of the RSJC model.
\end{abstract}

\section{Introduction.}

We have developed a model of picosecond Josephson tunnel junctions (SE model) based on a first order series expansion of the Werthamer equation [1]. It allows a precise numerical simulation of junctions with intrinsic switching time down to one picosecond and constitutes an efficient tool in the simulation of full circuits $[2,3]$. In the preliminary steps of circuit design, it is often useful to evaluate the switching performances of junctions using approximate analytic expressions of their characteristic times, namely the turn-on-delay $\left(t_{\mathrm{od}}\right)$ and the rise time $\left(t_{\mathrm{r}}\right)$. Such expressions are available for the RSJC model which describes slower junctions of characteristic time $t_{\mathrm{c}}=R_{\mathrm{N}} \times C>5 \mathrm{ps}$, where $R_{\mathrm{N}}$ and $C$ are the normal resistance and the capacitance of the junction. We present here for the SE model a set of analytic expressions of these characteristic times in the conditions of loading, bias and drive frequently met in Josephson direct coupled logic circuits. We compare these expressions with the results of numerical simulations and the RSJC model.
2. Equation of the Josephson current in the SE model.

The current equation governing switching of a Josephson junction using the SE model is [1] :

$$
\begin{array}{r}
I(t)=I_{\mathrm{c}}(V) \sin (\varphi(t))+I_{\mathrm{pqp}}(V) \cos (\varphi(t))+ \\
+I_{\mathrm{qp}}(V)+(C+A) \times \frac{\mathrm{d} V}{\mathrm{~d} t}+I_{\mathrm{s}}
\end{array}
$$

with

$$
\begin{aligned}
A=\frac{\hbar}{2 e} \times(- & \frac{\mathrm{d}^{2} I_{\mathrm{c}}(V)}{\mathrm{d} V^{2}} \cos (\varphi(t))- \\
& \left.-\frac{\mathrm{d}^{2} I_{\mathrm{pqp}}(V)}{\mathrm{d} V^{2}} \sin (\varphi(t))-\frac{\mathrm{d}^{2} I_{\mathrm{qpr}}(V)}{\mathrm{d} V^{2}}\right)
\end{aligned}
$$

and

$$
\frac{\mathrm{d} \varphi}{\mathrm{d} t}=-\frac{2 \mathrm{eV}(t)}{\hbar}
$$

$V(t)$ and $\varphi(t)$ are the voltage and superconducting phase across the junction.

In equation (1), $I(t)$ represents the total current (bias current + control current) feeding the junction. 
$I_{\mathrm{c}}(V), I_{\mathrm{qp}}(V), I_{\mathrm{pqp}}(V), I_{\mathrm{qpr}}(V)$ are the four standard Josephson current components which are voltage dependent [4]. $I_{\mathrm{s}}=V / R_{\mathrm{s}}$ is the current flowing in the resistance $R_{\mathrm{s}}$ shunting the junction in many current-injection logic gates. $C$ is the junction capacitance. The calculation of the current components and their voltage derivatives in equation (1) is made using BCS theory and Harris formulas [4]. Normalized values of these quantities versus voltage constitute tables and such data are given for a niobium-lead technology in table I of [1].

Table I.- Comparison of the turn on delay given by the SE model (Eq. (9)) and by the RSJC model as a function of $t_{\mathrm{c}}=R_{\mathrm{N}} \times C$.

\begin{tabular}{|l|c|c|c|c|}
\hline$R_{\mathrm{N}} \times C$ & $1 \mathrm{ps}$ & $2 \mathrm{ps}$ & $5 \mathrm{ps}$ & $10 \mathrm{ps}$ \\
\hline$t_{\mathrm{od}}(\mathrm{SE})$ & $1.7 \mathrm{ps}$ & $2.38 \mathrm{ps}$ & $4.17 \mathrm{ps}$ & $6.9 \mathrm{ps}$ \\
\hline$t_{\mathrm{od}}(\mathrm{RSJC})$ & $1.31 \mathrm{ps}$ & $2.08 \mathrm{ps}$ & $3.95 \mathrm{ps}$ & $6.8 \mathrm{ps}$ \\
\hline
\end{tabular}

\section{Analytical expressions of the turn-on-delay.}

\subsection{UNLOADED JUNCTIONS $\left(R_{\mathrm{s}}=\infty\right)$.}

a) Junction biased at critical current $I_{\mathrm{c}}$ and driven by a current step $\delta I_{\mathrm{c}}$ - - In this simple situation we may use the same approach as in the RSJC model by McDonald et al. [5] and introduce easily the term $A$ of equation (1). The phase at time $t=0$ is $-\pi / 2$ and we determine the time at which $\varphi=-\frac{\pi}{2}-\frac{1}{2}$. In equation (1), $I_{\mathrm{pqp}} \times \cos (\varphi(t))=0$ and $I_{\mathrm{qp}}=0$ since the calculation is made at $V=0$. The new term $A$ is a function of $V$ and $t$ and there is no exact analytic solution of the resulting system of Josephson equations. We have determined an average value $A_{0}$ of $A$ in the low voltage range (0, $100 \mu \mathrm{V})$ and phase range $\left(-\frac{\pi}{2},-\frac{\pi}{2}-\frac{1}{2}\right)$,

$$
A_{0}=3 \times 10^{-15} \times\left(I_{\mathrm{c}} / V_{\mathrm{g}}^{2}\right) \text { in farads }
$$

where $I_{\mathrm{c}}$ is the junction critical current and $V_{\mathrm{g}}$ the gap voltage.

The term $A_{0}$ acts as an added capacitance to the junction static capacitance $C$ and allows an easy comparison with the analytical expressions of the RSJC model. The above value of $A_{0}$ is confirmed by simulations using a numerical calculation of equation (1).

With $A=A_{0}$ equation (1) can be written as

$$
I_{\mathrm{c}}(1+\delta)=I_{\mathrm{c}}+\left(C+A_{0}\right) \times \frac{\mathrm{d} V}{\mathrm{~d} t}
$$

which gives :

$$
\varphi(t)=-\frac{\pi}{2}-\frac{e I_{\mathrm{c}} t^{2}}{\hbar\left(C+A_{0}\right)} .
$$

The expression of the turn-on-delay given by the SE model gives :

$$
t_{\mathrm{od}}(\mathrm{SE})=\left(\frac{\hbar\left(C+A_{0}\right)}{2 e I_{\mathrm{c}}}\right)^{1 / 2} .
$$

Equation (1) can be compared with the $t_{\text {od }}$ given by the RSJC model :

$$
t_{\mathrm{od}}(\mathrm{RSJC})=\left(\frac{\hbar C}{2 e I_{\mathrm{c}}}\right)^{1 / 2} .
$$

In otherwords

$$
\frac{t_{\text {od }}(\mathrm{SE})}{t_{\text {od }(\mathrm{RSJC})}}=\left(1+\frac{A_{0}}{C}\right)^{1 / 2}=\left(1+\frac{2 \times 10^{-15}}{V_{\mathrm{g}} t_{\mathrm{c}}}\right)^{1 / 2}
$$

with $V_{\mathrm{g}}$ in volts and $t_{\mathrm{c}}=R_{\mathrm{N}} \times C$ in seconds.

The term $A_{0}$ which adds to the static capacitance $C$ has a negligible effect in junctions of large capacitance i.e. junctions with intrinsic time constant $t_{\mathrm{c}}>10 \mathrm{ps}$. On the other side, the effect of $A_{0}$ increases in junctions with $t_{\mathrm{c}}<10 \mathrm{ps}$. As an example, $A_{0}=C$ if $t_{\mathrm{c}}=1 \mathrm{ps}$ and $V_{\mathrm{g}}=2.5 \mathrm{mV}$. Figure 1 illustrates the increasing difference between equation (3) and equation (4) as a function of the product $V_{\mathrm{g}} \times t_{\mathrm{c}}$. It must be pointed out that equation (5) is independent of the amplitude of the current overdrive. However the term $A_{0}$ is noticeable only at weak voltage.

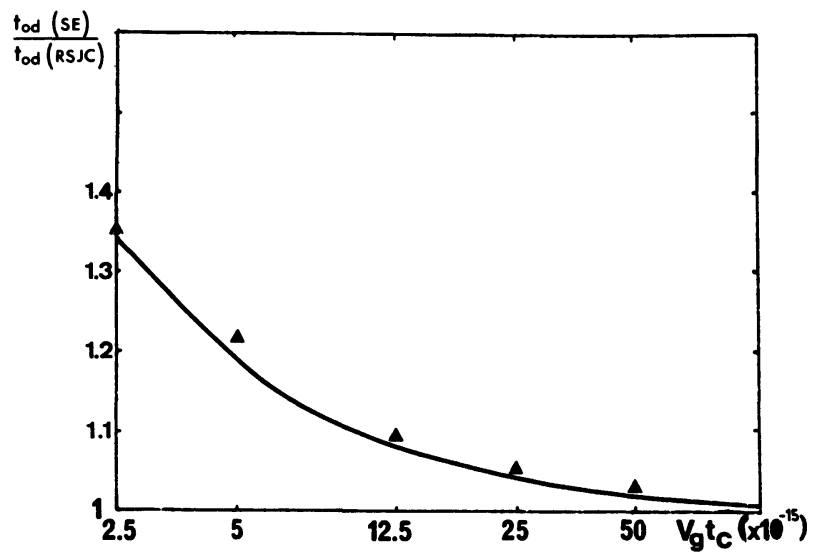

Fig. 1. - Comparison of the turn on delay $\left(t_{\mathrm{od}}\right)$ predicted by the SE model and by the RSJC model (full line) as a function of $V_{\mathrm{g}} \times t_{\mathrm{c}}=V_{\mathrm{g}} \times R_{\mathrm{N}} \times C$ (here $V_{\mathrm{g}}=2.5 \mathrm{mV}$ and $t_{\mathrm{c}}=1 \mathrm{ps}$ ). The junction is biased at the critical current and driven by a current step $\delta I_{\mathrm{c}}$. The triangle correspond to numerical simulations.

b) Junction biased at critical current $I_{\mathrm{c}}$ and driven by a linear current ramp versus time $a I_{\mathrm{c}} \times t$. - The equation of currents is similar to equation (2) and can be written as :

$$
I_{\mathrm{c}}(1+a t)=\left(C+A_{0}\right) \times \frac{\mathrm{d} V}{\mathrm{~d} t}+I_{\mathrm{c}}
$$


which gives

$$
\varphi(t)=-\frac{\pi}{2}-\frac{a e I_{\mathrm{c}}}{\hbar\left(C+A_{0}\right)} \times \frac{t^{3}}{3}
$$

and

$$
t_{\mathrm{od}}(\mathrm{SE})=\left(\frac{3}{2} \times \frac{\hbar\left(C+A_{0}\right)}{a e I_{\mathrm{c}}}\right)^{1 / 3}
$$

with $A_{0}=0$ in equation (7), we obtains the expression that represents $t_{\mathrm{od}}(\mathrm{RSJC})$. In this case we have :

$$
\frac{t_{\mathrm{od}}(\mathrm{SE})}{t_{\mathrm{od}}(\mathrm{RSJC})}=\left(1+\frac{2.5 \times 10^{-15}}{V_{\mathrm{g}} t_{\mathrm{c}}}\right) .
$$

The comparison of equations (7)-(8) with equations (3)-(5) shows that the influence of the term $A_{0}$ is now attenuated since the exponent is $1 / 3$ instead of $1 / 2$. Therefore the difference between the RSJC and the SE model rises more slowly when $t_{\mathrm{c}}$ decreases. Figure 2 illustrates this evolution.

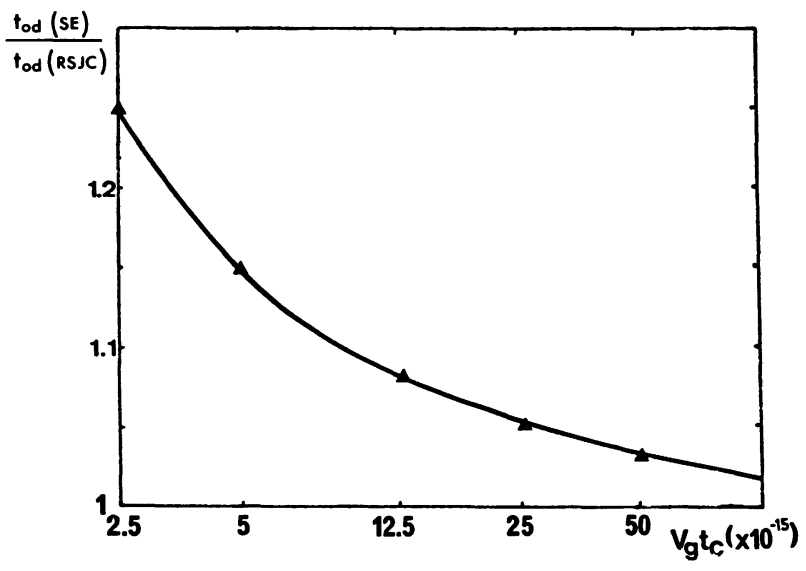

Fig. 2. - Comparison of the $t_{\mathrm{od}}$ predicted by the SE model and by the RSJC model. The junction is driven by a linear current ramp $a \times I_{\mathrm{c}} \times t$ (full line). The triangles correspond to numerical simulations.

c) Junction biased under the critical current $\left(I_{\mathrm{p}}=\alpha I_{\mathrm{c}}\right)$ and driven by a linear current ramp $a^{\prime} \times I_{\mathrm{p}} \times t$. - This case corresponds to many junctions in direct coupled logic gates. $A$ junction DC bias of $I_{\mathrm{p}}=0.8 I_{\mathrm{c}}$ is a trade-off to obtain optimum speed performances with wide margins which prevent of accidental switching.

The knowledge of the junction phase variation with bias current requires the use of a series expansion of $\sin (\varphi)$ as the phase variation is larger than in the previous cases,

$$
\sin (\varphi)=-1+\frac{\left(\varphi-\varphi_{0}\right)^{2}}{2}
$$

The accuracy of this expression is better than $5 \%$ for $-2.5<\varphi<-0.65$, which corresponds to junc- tions biased in the interval $0.6 I_{\mathrm{c}}<I_{\mathrm{p}}<I_{\mathrm{c}}$ and covers the useful bias current range of DCL gates. Then the equation of currents in the junction becomes.

$$
\begin{aligned}
I_{\mathrm{p}}\left(1+a^{\prime} t\right)=-I_{\mathrm{c}}(-1+ & \left.\frac{\left(\varphi-\varphi_{0}\right)^{2}}{2}\right)+ \\
& +\left(C+A_{0}^{\prime}\right) \times \frac{\mathrm{d} V}{\mathrm{~d} t} .
\end{aligned}
$$

The current components $I_{\mathrm{p}}, I_{\mathrm{qp}}$ are again neglected since $V=0$. The term $A$ depends on the junction phase and we have reevaluated its mean value $A_{0}^{\prime}$ in the phase interval $-2.5<\varphi<-0.65$, the new value $A_{0}^{\prime}$ is :

$$
A_{0}^{\prime}=3.26 \times 10^{-15} \times \frac{I_{\mathrm{c}}}{V_{\mathrm{g}}^{2}} .
$$

Using the relationship between $I_{\mathrm{c}}$ and $C$

$$
C=4 t_{\mathrm{c}} \times \frac{I_{\mathrm{c}}}{\pi V_{\mathrm{g}}} .
$$

The equation (9) becomes (in MKSA units) :

$$
\begin{aligned}
& \frac{I_{\mathrm{p}}}{I_{\mathrm{c}}}\left(1+a^{\prime} t\right)=1-\frac{\left(\varphi-\varphi_{0}\right)^{2}}{2}-\frac{\hbar}{2 e V_{\mathrm{g}}} \times \\
& \times\left(\frac{4 t_{\mathrm{c}}}{\pi}+\frac{2.17 \times 10^{-15}}{V_{\mathrm{g}}}\right) \times \frac{\mathrm{d}^{2} \varphi}{\mathrm{d} t^{2}} .
\end{aligned}
$$

We have calculated this expression with $I_{\mathrm{p}}=0.8 I_{\mathrm{c}}$ and a control current ramp such that $I_{\mathrm{p}}\left(1+a^{\prime} t\right)=1.2 I_{\mathrm{c}}$ at $t=t_{\mathrm{c}}(20 \%$ overdrive $)$. The resulting $t_{\mathrm{od}}$ versus $t_{\mathrm{c}}$ is given in table $\mathrm{I}$ and is compared with the RSJC model. The figure 3 represents the evolution of the ratio $t_{\text {od }}(\mathrm{SE}) / t_{\text {od }}(\mathrm{RSJC})$. The RSJC model underestimates the $t_{\text {od }}$ in a noticeable way when $V_{\mathrm{g}} \times$

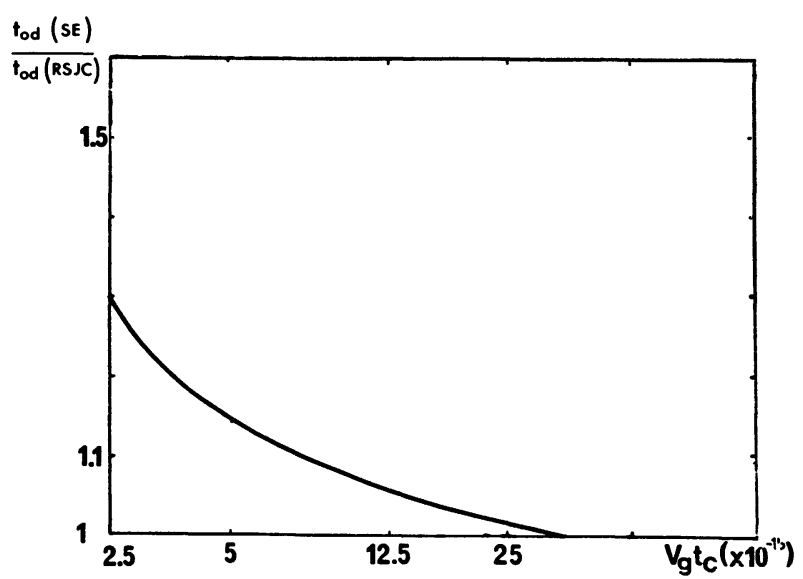

Fig. 3. - Comparison of the $t_{\text {od }}$ predicted by the SE model and by the RSJC model. The junction is biased under the critical current and driven by a current ramp (see Table I). 
$t_{\mathrm{c}}<5 \times 10^{-15}$ V.s. The larger values reached here by the ratio of $t_{\mathrm{od}}$ 's compared to the case b (Fig. 2) is due only to the steeper current $\operatorname{ramp}\left(a^{\prime}>a\right)$ in order to have the same current overdrive. It may be also pointed out from figures 1-3 that technologies based on larger gap superconductors (e.g. $\mathrm{NbN}$ or the new high Tc superconductors) will reach later the limits of the RSJC model than the $\mathrm{Pb}$ or $\mathrm{Nb}$ technologies.

3.2 Heavily loAded Junctions. - Fast junctions have small capacitance and numerical calculations show that in such junctions loaded with a resistive shunt $R_{\mathrm{s}} \ll R_{\mathrm{N}}$, the capacitive term of equation (1) and $a$ fortiori the term $A$ of the SE model can be neglected during the $t_{\mathrm{od}}$ since :

$$
V / R_{\mathrm{s}} \gg\left(C+A_{0}\right) \times \frac{\mathrm{d} V}{\mathrm{~d} t} .
$$

Then the equation of currents during the $t_{\mathrm{od}}$ is the same in the SE model and the RSJC model.

a) Junction biased at critical current $I_{\mathrm{c}}$ and driven with a current step. - The equation of currents writes

$$
I_{\mathrm{c}}(1+\delta)=I_{\mathrm{c}}+\frac{V}{R_{\mathrm{s}}} .
$$

The phase $\varphi(t)$ writes

$$
\varphi(t)=-\frac{2 e}{\hbar} \times R_{\mathrm{s}} \times \delta I_{\mathrm{c}} \times t-\frac{\pi}{2}
$$

giving a $t_{\text {tod }}$ :

$$
t_{\mathrm{od}}=\frac{\hbar}{\pi e V_{\mathrm{g}} \delta} \times \frac{R_{\mathrm{N}}}{R_{\mathrm{s}}} .
$$

This result underlines that in a loaded junction $t_{\text {od }}$ is determined by the current overdrive and the ratio $R_{\mathrm{N}} / R_{\mathrm{s}}$. In niobium DCL loaded gates, equation (11) shows that $t_{\text {od }}$ lies often in the ten picosecond range and is independent of the intrinsic speed of the junction. Then picosecond junctions cannot make very fast a circuit having loaded junctions. This limitation in the reduction of $t_{\text {od }}$ has already been reported in several publications owing to numerical simulations [6] or complex integral expressions [7]. Equation (11) appears to be the first simple analytical expression of the $t_{\text {od }}$ of a shunted junction. It allows its quick evaluation in the design of a new circuit. We have tested the validity of equation (11) against numerical calculating of equation (1) for different junction speeds $\left(\beta_{\mathrm{c}}\right)$, shunt and current overdrive values. The results presented in table II show the equation (11) may be used with confidence in the broad range of presented parameter values corresponding to current injection logic gates.
Table II. - Turn on delay of a loaded junction biased at the critical current as a function of the

\begin{tabular}{|c|c|c|c|c|}
\hline \multicolumn{5}{|l|}{$R_{\mathrm{s}} / R_{\mathrm{N}}=0.1$} \\
\hline$R_{\mathrm{N}} \times C$ & $1 \mathrm{ps}$ & 3 ps & $5 \mathrm{ps}$ & Eq. (11) \\
\hline 0.1 & 7 ps & $7.3 \mathrm{ps}$ & $7.6 \mathrm{ps}$ & 8.4 ps \\
\hline 0.2 & $4 \mathrm{ps}$ & $4.3 \mathrm{ps}$ & $4.5 \mathrm{ps}$ & $4.3 \mathrm{ps}$ \\
\hline 0.3 & $2.9 \mathrm{ps}$ & $3.1 \mathrm{ps}$ & $3.3 \mathrm{ps}$ & $2.8 \mathrm{ps}$ \\
\hline 0.5 & $1.9 \mathrm{ps}$ & $2.1 \mathrm{ps}$ & $2.3 \mathrm{ps}$ & $1.7 \mathrm{ps}$ \\
\hline
\end{tabular}
current step drive $\delta I_{\mathrm{c}}$. The predictions of equation (11) in the last column are compared to numerical simulations for different values of $R_{\mathrm{N}} \times C$.

b) Junction biased under the critical current $\left(I_{\mathrm{p}}=\alpha I_{\mathrm{c}}\right)$ and driven by a current step $\delta I_{\mathrm{c}} .-$ The junction dynamic of the loaded junction is slow and the rise time of the current drive has a negligible influence. Therefore we consider only a current step drive. The equation of currents in the junction writes now :

$$
I_{\mathrm{c}}(\alpha+\delta)=I_{\mathrm{c}} \times \sin (\varphi)+\frac{V}{R_{\mathrm{s}}} .
$$

It gives a $t_{\mathrm{od}}$

$$
\begin{aligned}
t_{\mathrm{od}}=\frac{\hbar}{\pi e V_{\mathrm{g}}} & \times \frac{R_{\mathrm{N}}}{R_{\mathrm{s}}} \times \frac{4}{\left((\alpha+\delta)^{2}-1\right)^{1 / 2}} \times \\
& \times\left(\tan ^{-1}\left(\frac{v}{b}\right)-\tan ^{-1}\left(\frac{v_{0}}{b}\right)\right)
\end{aligned}
$$

with

$$
\begin{aligned}
\alpha & =\sin \left(\varphi_{0}\right) \\
v & =\tan \left(\frac{1}{2}\left(\frac{\pi}{2}+\frac{1}{2}\right)\right)-\frac{1}{\alpha+\delta} \\
v_{0} & =\tan \left(\frac{\varphi_{0}}{2}\right)-\frac{1}{\alpha+\delta} \\
b & =\left((\alpha+\delta)^{2}-1\right)^{1 / 2} /(\alpha+\delta) .
\end{aligned}
$$

The figure 4 represents the evolution of the $t_{\text {od }}$ depending on the overdrive $\delta$, following the relation $\left(11^{\prime}\right)$, compared with the result of the numerical simulation. The junction is biased at $\alpha=0.7$.

\section{Analytical expressions of the junction rise time.}

Relatively simple expressions of the rise time $t_{\mathrm{r}}$ of picosecond junctions can also be obtained. In this section, the integration of equation (1) is made assuming that the average values of $\sin (\varphi)$ and $\cos (\varphi)$ are zero during the voltage rise. This approximation is well verified in large $t_{\mathrm{c}}$ junctions as several periods of the Josephson oscillation occur in the voltage rise. It becomes less accurate as $t_{\mathrm{c}}$ decreases and if $t_{\mathrm{c}}<1 \mathrm{ps}$ the device rise time is 


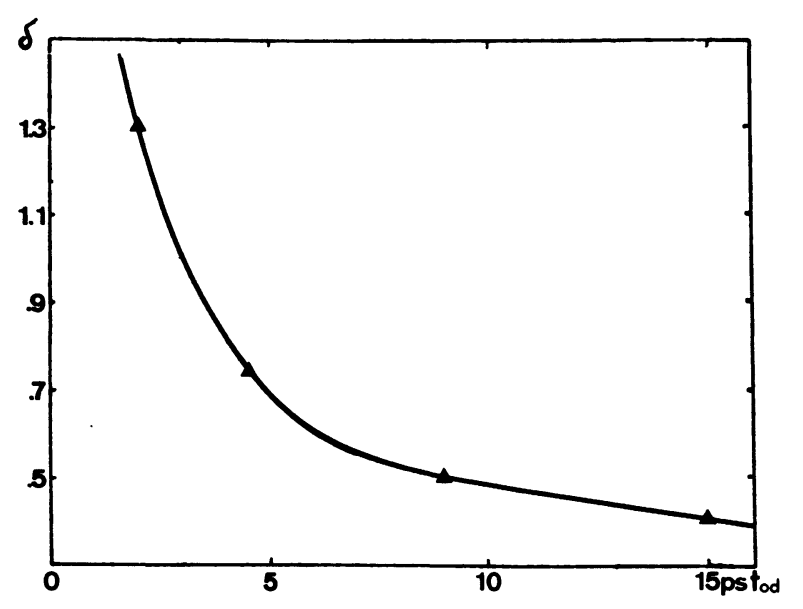

Fig. 4. $-t_{\text {od }}$ of a loaded junction with $R_{\mathrm{N}} / R_{\mathrm{s}}=10$ and biased at $0.7 I_{\mathrm{c}}$ versus step drive current $\delta I_{\mathrm{c}}$ (full line). The triangles correspond to numerical simulations.

shorter than a full period of the phase across the junction at $V=V_{\mathrm{g}}$ so that the approximation is not any more valid. Therefore the expressions which we give here represent only estimates of the rise time in junctions with $t_{\mathrm{c}}>1 \mathrm{ps}$. However numerical dynamic simulations of equation (1) show that they may be used with confidence.

As it may be seen in section 3, for small overdrive, the $t_{\text {od }}$ of a picosecond junction is large enough so that the drive current has reached its nominal value when the voltage rise occurs. Therefore any current drive shape gives a similar result as a step current drive $\delta I_{\mathrm{c}}$ which is considered in the following. We shall define rise times as in semiconductor circuits i.e. in the voltage interval $\left(0.1 V_{\mathrm{f}}-0.9 V_{\mathrm{f}}\right)$ where $V_{\mathrm{f}}$ is the final voltage.

4.1 LOADED JUNCTION. - This situation is frequently met in the input junction of direct coupled logic gates. The shunt $R_{\mathrm{s}}$ may carry after switching a current which is a large fraction of the critical $I_{\mathrm{c}}$ at voltages $V \leqslant V_{\mathrm{g}}$. After switching the junction is biased below the gap voltage i.e.

$$
R_{\mathrm{s}} \times I_{\mathrm{c}}(1+\delta) \ll V_{\mathrm{g}}
$$

and the equation of currents gives

$$
R_{\mathrm{s}} \times I_{\mathrm{c}}(1+\delta)=V+R_{\mathrm{s}}\left(C+A_{\mathrm{r}}\right) \times \frac{\mathrm{d} V}{\mathrm{~d} t}
$$

where $A_{\mathrm{r}}$ is the average value of $A$ over the voltage range $100 \mu \mathrm{V}<V<V_{\mathrm{f}}$ and $V_{\mathrm{f}}$ is the final voltage at the end of the switching event. $V_{\mathrm{f}}$ is mostly determined by the shunt resistance $R_{\mathrm{s}}$

$$
V_{\mathrm{f}}=R_{\mathrm{s}} \times I_{\mathrm{c}} \times(1+\delta) .
$$

Defining

$$
T_{\mathrm{r}}=R_{\mathrm{s}} \times\left(C+A_{\mathrm{r}}\right)
$$

one obtains from equations (13)-(15)

$$
V=V_{\mathrm{f}} \times\left(1+\exp \left(-t / T_{\mathrm{r}}\right)\right)
$$

and the rise time $t_{\mathrm{r}}$ from $0.1 V_{\mathrm{f}}$ to $0.9 V_{\mathrm{f}}$ is

$$
t_{\mathrm{r}}=2.3 T_{\mathrm{r}} \text {. }
$$

In equation (15) $A_{\mathrm{r}}$ may depend strongly on $V_{\mathrm{f}}$ through the voltage derivative of $I_{\mathrm{qpr}}$ :

$$
A_{\mathrm{r}}\left(V_{\mathrm{f}}\right)=-\frac{\hbar I_{\mathrm{c}}}{2 e V_{\mathrm{g}}^{2}} \times \frac{\mathrm{d}^{2} I_{\mathrm{qpr}}\left(V_{\mathrm{f}}\right)}{\mathrm{d} V^{2}} .
$$

The time constant $T_{\mathrm{r}}$ may be rewritten as a function of the RSJC time constant of the shunted junction

with

$$
\begin{gathered}
t_{\mathrm{c}}^{\prime}=R_{\mathrm{s}} \times C \\
T_{\mathrm{r}}=t_{\mathrm{c}}^{\prime} \times\left(1+k\left(V_{\mathrm{f}}\right)\right) \\
\mathrm{k}\left(V_{\mathrm{f}}\right)=A_{\mathrm{r}}\left(V_{\mathrm{f}}\right) / C .
\end{gathered}
$$

The figure 5 shows the variation of the quantity $k\left(V_{\mathrm{f}}\right) \times t_{\mathrm{c}} \times V_{\mathrm{g}}$ as a function of $V_{\mathrm{f}} / V_{\mathrm{g}}$. In the voltage range $0.1 V_{\mathrm{g}}<V_{\mathrm{f}}<0.9 V_{\mathrm{g}}$ we may write in MKSA units

$$
0.6 \times 10^{-15}<t_{\mathrm{c}} \times V_{\mathrm{g}} \times k\left(V_{\mathrm{f}}\right)<2 \times 10^{-15} .
$$

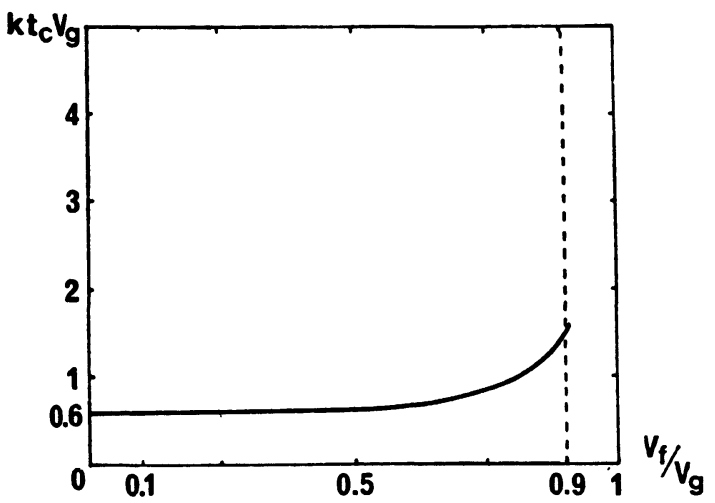

Fig. 5. - Evaluation of the rise time of a loaded junction. Variation of the factor $k\left(V_{\mathrm{f}}\right) \times t_{\mathrm{c}} \times V_{\mathrm{g}}$ as a function of $V_{\mathrm{f}} / V_{\mathrm{g}}$

If $t_{\mathrm{c}}=1 \mathrm{ps}$ and $V_{\mathrm{g}}=2.5 \mathrm{mV}$ the above inequality gives

$$
1.24 t_{\mathrm{c}}^{\prime}<T_{\mathrm{r}}<1.8 t_{\mathrm{c}}^{\prime}
$$

which illustrates the large variation of $T_{\mathrm{r}}$ versus $V_{\mathrm{f}}$. The increase of $T_{\mathrm{r}}$ is only important if $t_{\mathrm{c}}$ approachs $1-2 \mathrm{ps}$ and if the voltage $V_{\mathrm{f}}$ is near $V_{\mathrm{g}}$. The figure 6 shows the variation of $t_{\mathrm{r}} / t_{\mathrm{c}}^{\prime}$ given by equation (19) as a function of $V_{\mathrm{f}} / V_{\mathrm{g}}$ and $t_{\mathrm{c}}$.

4.2 UNLOADED JUNCTION. - This situation is met in a new structure of DCL gates with unloaded input 


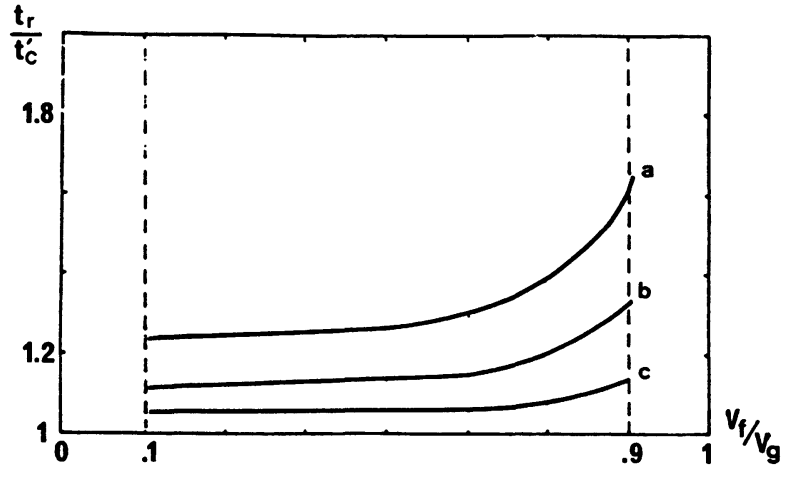

Fig. 6. - Rise time of a loaded junction driven by a current step. Comparison of the predictions given by the SE model $\left(t_{\mathrm{r}}\right)$ and by the RSJC model $\left(t_{\mathrm{c}}^{\prime}\right)$ as a function of the final voltage $\left(V_{\mathrm{f}} / V_{\mathrm{g}}\right)$. The parameter is the intrinsic junction time constant $t_{\mathrm{c}}=R_{\mathrm{N}} \times C: t_{\mathrm{c}}=1 \mathrm{ps} \quad$ (a), $t_{\mathrm{c}}=2 \mathrm{ps}(\mathrm{b}), t_{\mathrm{c}}=5 \mathrm{ps}$ (c).

junction to minimize the turn on delay [2]. The voltage across an unloaded junction may often reach values above $V_{\mathrm{g}}$. Since the current components have strongly non linear variations, the equation of currents takes different forms respectively at voltages smaller and larger than $V_{\mathrm{g}}$. For $V<0.9 V_{\mathrm{g}}$

$$
I_{\mathrm{c}}(1+\delta)=\left(C+A_{\mathrm{r}}\right) \times \frac{\mathrm{d} V}{\mathrm{~d} t}
$$

and

$I_{\mathrm{c}}(1+\delta)=\frac{V}{R_{\mathrm{N}}}+\left(C+A_{\mathrm{r}}\right) \times \frac{\mathrm{d} V}{\mathrm{~d} t}$

for

$$
V>1.1 V_{\mathrm{g}} \text {. }
$$

In the voltage range $0.9 V_{\mathrm{g}}<V<1.1 V_{\mathrm{g}}$, we use in equation (1) the adiabatic approximation to avoid singularities in the $\operatorname{term} A$ (see Fig. 6). This introduces only a small error since the voltage interval is narrow. Then we deduce the time $t_{1}$ to reach $0.9 V_{\mathrm{g}}$ and the time $t_{2}$ from $1.1 V_{\mathrm{g}}$ to $0.9 V_{\mathrm{f}}$ :

$$
\begin{gathered}
t_{1}=0.9 V_{\mathrm{g}} \times \frac{C+A_{\mathrm{r}}\left(0.9 V_{\mathrm{g}}\right)}{I_{\mathrm{c}}(1+\delta)} \\
t_{2}=R_{\mathrm{N}} \times\left(C+A_{\mathrm{r}}\left(0.9 V_{\mathrm{f}}\right)\right) \times \log \left(\frac{V_{\mathrm{f}}-1.1 V_{\mathrm{g}}}{0.1 V_{\mathrm{f}}}\right)
\end{gathered}
$$

where $V_{\mathrm{f}}$ is the final voltage for an unloaded junction :

$$
V_{\mathrm{f}}=R_{\mathrm{N}} I_{\mathrm{c}}(1+\delta) \text { for } \delta>0.3
$$

The total rise time of the device depends only on the overdrive $\delta$ in an unloaded junction.

a) Small overdrive $(\delta<0.3)$. - In this situation, the final voltage across the device is $V_{\mathrm{g}}$ and the rise time is given by $t_{1}$ (Eq. (23)). It may be written in MKSA units using

$$
\begin{gathered}
V_{\mathrm{g}} / I_{\mathrm{c}}=4 R_{\mathrm{N}} / \pi \\
t_{\mathrm{r}}=1.15 t_{\mathrm{c}}\left(1+\frac{1.83 \times 10^{-15}}{t_{\mathrm{c}} \times V_{\mathrm{g}}}\right) /(1+\delta) .
\end{gathered}
$$

Equation (26) shows that the SE model introduces a correction term depending on $V_{\mathrm{g}} \times t_{\mathrm{c}}$. The increase of the rise time relatively to the prediction of RSJC model rises strongly at small values of $t_{\mathrm{c}}$ and $V_{\mathrm{g}}$. It reaches $70 \%$ in a one picosecond niobium junction. However it must be pointed that the correction is less important in a large gap superconductor technology such as $\mathrm{NbN}$ due to the dependence on $V_{\mathrm{g}}$.

b) Moderate and large overdrive $(\delta>0.3)$. - In this case the final voltage across the junction is given by equation (25). The rise time is given by $t_{1}+t_{2}$ within $15 \%$ if we neglect the time when the voltage rises from $0.9 V_{\mathrm{g}}$ to $1.1 \mathrm{~V}_{\mathrm{g}}$.

$t_{\mathrm{r}}=t_{\mathrm{c}} \times\left(\frac{1.15}{1+\delta}\right) \times\left(1+\frac{1.83 \times 10^{-15}}{t_{\mathrm{c}} \times V_{\mathrm{g}}}\right)+$

$+\left(1+\frac{A_{\mathrm{r}}\left(0.9 V_{\mathrm{f}}\right)}{C}\right) \times \log \left(10-11 \times \frac{V_{\mathrm{g}}}{V_{\mathrm{f}}}\right)$.

For an overdrive larger than 1.5, the expression (27) may be simplified :

$$
t_{\mathrm{r}}=2.13 \times t_{\mathrm{c}} \times\left(1+\frac{0.72 \times 10^{-15}}{t_{\mathrm{c}} \times V_{\mathrm{g}}}\right) .
$$

The figure 7 shows the evolution of the rise time predicted by the SE model, $t_{\mathrm{r}}(\mathrm{SE})$, in units of the $t_{\mathrm{r}}$ (RSJC) versus overdrive $\delta$, using equations (23) and (24) and the approximated transit time corresponding to the voltage interval $\left(0.9 \mathrm{~V}_{\mathrm{g}}-1.1 \mathrm{~V}_{\mathrm{g}}\right)$. It appears that the RSJC model underestimates

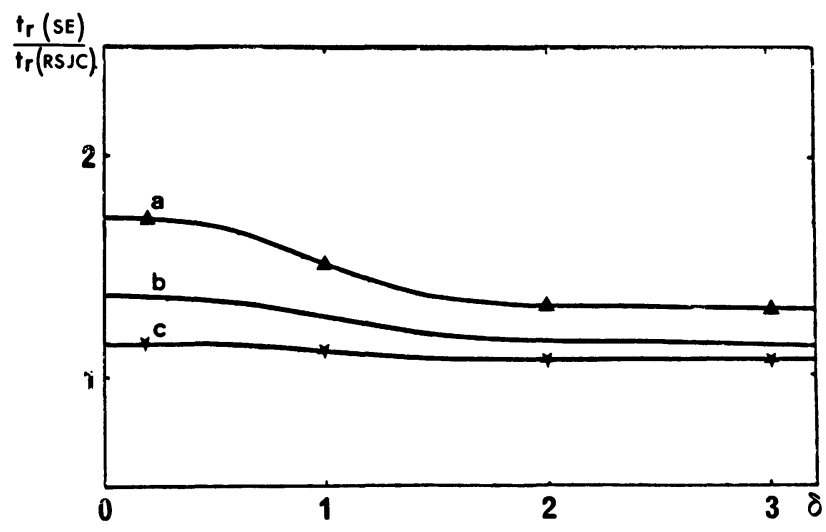

Fig. 7. - Comparison of the rise time $t_{\mathrm{r}}$ of an unloaded junction predicted by the SE model and the RSJC model with large current overdrive. This is the case of the input junction of DCL gates. The parameter is $t_{\mathrm{c}}=1 \mathrm{ps}$ (a), $t_{\mathrm{c}}=2 \mathrm{ps}$ (b), $t_{\mathrm{c}}=5 \mathrm{ps}$ (c). The triangles correspond to numerical simulations of (a) and stars to simulations of (c). 
strongly $t_{\mathrm{r}}$ in junction with $t_{\mathrm{c}}=1 \mathrm{ps}$ at moderate overdrive $(\delta<1)$.

\section{Conclusion.}

We have established analytical expressions of the two characteristic times which define the dynamics of Josephson junctions in the case of picosecond (1-5 ps) devices, namely the turn on delay and the rise time. Such expressions are useful in the first steps of the design of circuits optimized in terms of speed performance. They also help to understand the limitations in the transfer of speed performances from an isolated Josephson junction to a junction embedded in a circuit.

\section{References}

[1] De Lustrac, A., Crozat, P., Adde, R., Revue Phys. Appl. 21 (1986) 319.

[2] De Lustrac, A., Crozat, P., Adde, R., Superconducting Quantum Interference Devices and their Applications, SQUID 1985, Editors H. D. Hahlbohm and H. Lübbig, Walter de Gruyter and Co, Berlin (1985) 1097.
[3] De Lustrac, A., Adde, R., IEEE Trans. Magn. 21 (1985) 566.

[4] Harris, R. E., Phys. Rev. B 11 (1975) 3329.

[5] McDonald, D. G., Peterson, R. L., Hamilton, C. A., Harris, R. E., KAUTZ, R. L., IEEE Trans. Electron Devices ED 27 (1980), 1945.

[6] Ko, VAN DuZER, IEEE Trans. Magn. (1985).

[7] Sone, J., J. Appl. Phys. 57 (1985) 5028. 